\title{
Prosocialness and Happiness in Chilean Student Teachers
}

\author{
Manuel Mieres-Chacaltana ${ }^{1,2}$, Sonia Salvo-Garrido ${ }^{3 *}$ and Marianela Denegri ${ }^{4}$ \\ ${ }^{1}$ Departamento de Educación Media, Universidad Católica de Temuco, Temuco, Chile, ${ }^{2}$ Programa de Doctorado en Ciencias \\ Sociales, Universidad de La Frontera, Temuco, Chile, ${ }^{3}$ Departamento de Matemática y Estadística, Laboratorio de \\ Investigación en Ciencias Sociales Aplicadas (LICSA), Universidad de La Frontera, Temuco, Chile, ${ }^{4}$ Núcleo Científico y \\ Tecnológico en Ciencias Sociales, Universidad de La Frontera, Temuco, Chile
}

The aim of the study was to evaluate the relation between prosocialness and happiness in a sample of student teachers $(N=224$, age $=21.42)$. Adapted versions of a prosocialness scale and another on happiness were used. A structural equations model was estimated that presented a suitable fit $(C F I=0.951 ; T L I=0.944$ and $R M S E A=0.065)$. The results yielded a positive relation between prosocialness and happiness. Its implications for initial teacher training are discussed.

Keywords: prosocialness, happiness, education, teaching, initial teacher training

\section{OPEN ACCESS}

Edited by:

Margarida Pocinho,

University of Madeira, Portugal

Reviewed by:

Diana Martella,

Autonomous University of Chile, Chile Andreja Brajsa Zganec,

Institute of Social Sciences Ivo Pilar (IPI), Croatia

*Correspondence: Sonia Salvo-Garrido sonia.salvo@ufrontera.cl

Specialty section:

This article was submitted to Educational Psychology, a section of the journal Frontiers in Psychology

Received: 21 July 2021 Accepted: 13 October 2021 Published: 05 November 2021

Citation: Mieres-Chacaltana M, Salvo-Garrido $S$ and Denegri M (2021) Prosocialness and Happiness in Chilean Student Teachers.

Front. Psychol. 12:745163. doi: 10.3389/fpsyg.2021.745163

\section{INTRODUCTION}

Prosocialness is defined as a voluntary behavior meant to benefit someone else (Dovidio et al., 2006; Caprara and Steca, 2007; Eisenberg et al., 2015). These benefits can be on both the physical and emotional levels (Catalano et al., 2004; Caprara et al., 2005; Benson et al., 2006). Its study has become important in the last two decades given that these behaviors are desirable and beneficial to society (Eisenberg et al., 2006). It has been stated that prosocial behaviors affect the increase in happiness and well-being (Lyubomirsky, 2001; Lyubomirsky and Layous, 2013).

Happiness has been approached from three psychological perspectives: hedonic, eudaimonic, and flourishing. The first, reduces it to the pursuit of pleasure and the avoidance of pain (Waterman, 2008; Goodman et al., 2018). In contrast, the eudaimonic approach puts the focus on self-actualization and the actualization of human potential (Ryan and Deci, 2001). Consequently, it conceptualizes happiness as a state of fullness of personal functioning and valuing the meaning of life (Ryan and Deci, 2001; Waterman, 2008). Research has also developed complementary propositions (Keyes et al., 2002). Flourishing is one of the designations used to identify this integrated perspective (Seligman, 2011). In the context of the present research, happiness is defined from a broad orientation, encompassing elements of these three streams. That is, as the experience of joy, satisfaction, positive well-being, combined with the feeling that our life is good, meaningful, and worth living (Lyubomirsky, 2008).

At societal level, prosocialness promotes civic virtue, which in turn is positively associated with happiness (Simon and Mobekk, 2019; Lubian, 2020); moreover, it constitutes an effective way to increase happiness sustainably (Lai et al., 2020), which can also involve the economic dimension (Aknin et al., 2020; Dunn et al., 2020). This is relevant since a common goal of human beings is to achieve happiness (Buss, 2000). It should be emphasized that happy people are more successful on different vital planes (Lyubomirsky et al., 2005a): They adapt better to everyday situations and are more resilient to negative experiences (Abbe et al., 2003; Lyubomirsky et al., 2005b; Nielsen and Christensen, 2021). 
Based on the previous research, Unanue et al. (2021) studied the relationship between prosociality and happiness applied to the organizational environment. Using a longitudinal model, they considered the concepts of hedonic, eudaimonic, and flourishing happiness and their relationship with prosocial behaviors at work. These proved to be positive predictors of the three types of happiness. In turn, the three types of happiness positively predicted such prosocial behaviors. This model suggests the existence of a virtuous circle of prosociality and well-being in the workplace.

In its relation to education, several studies have agreed on the positive or advantageous aspects of prosocialness. During childhood, for example, it is associated with the positive self-concept (Garaigordobil and García De Galdeano, 2006) and with a better psychosocial adjustment in children and adolescents (Eisenberg and Fabes, 1998; Xiong et al., 2021), as well as with a superior display of social skills and group integration (Plazas et al., 2010) and greater academic achievements by preventing depression and transgressive behavior (Bandura et al., 1996; Cappella et al., 2013; FlórezDonado et al., 2018; Deng et al., 2021). More concretely, the promotion of prosocialness at school strengthens civic bonds (Luengo et al., 2014) and a better school climate (Luengo et al., 2017). Therefore, it promotes safety, healthy relationships, and the efforts for scholastic improvement (Cohen et al., 2009; Thapa et al., 2013). Consequently, it is to be expected that levels of happiness and well-being will improve in all the actors involved. This is because the cognitive and emotional advantages derived from prosocialness radiate especially to those who are closer to prosocial people (Chancellor et al., 2018). For others, both children and adolescent students, the existing positive relation between prosocial behaviors and self-assessed happiness has been stated (Krettenauer et al., 2019). This relation appears to be positively associated with strength of character, which contributes to coping better with harassment and intimidation in schools (García-Vázquez et al., 2020).

Given the theoretical and empirical background, this study sought to evaluate the relation between prosocialness and happiness in a sample of student teachers. The purpose was to generate knowledge that serves as input to orient future processes of initial teacher training in relation to the dimensions studied. Limiting the issue to the one described also accommodates the recommendations to deepen the study of prosocialness in specific milieus and to address the problem of its measurement (Auné et al., 2014), in particular in adulthood (Caprara et al., 2005). In this respect, it should be added that $86 \%$ of Chilean university students including student teachers - are aged between 18 and 29 years (Ministerio de Educación de Chile, 2017). This age range corresponds to so-called emerging adulthood, a transitional stage to adult life. This is characterized as being culturally constructed due to the search for identity and the consolidation of traits that will accompany the individual into adulthood (Barrera and Vinet, 2017); thus, the attitudinal, formative, and value-based trajectory to which the young people are exposed is important.

\section{MATERIALS AND METHODS}

\section{Participants}

The sample was comprised of 224 student teachers belonging to a university located in the Region of La Araucanía, Chile. $61.6 \%$ were women and $38.4 \%$ were men. The average age of the participants was 21.42 years with a standard (SD) of 2.48 years.

\section{Methodological Approach}

The methodological approach was correlational quantitative with a nonexperimental and cross-sectional design (Toro and Parra, 2010). A covariance structure model of interdependence was evaluated, since a correlation among the latent constructs that were studied was proposed (Lévy and Varela, 2006). Consequently, a confirmatory factor analysis (CFA) was applied because the factor loads or saturations were defined in advance (Lévy and Varela, 2006).

\section{Instruments}

Prosocialness was measured with an adapted version of the prosocialness scale for adults by Caprara et al. (2005). This was adjusted and validated in a previous study with Chilean student teachers $(N=859$; age $=20.72)$. It is a one-dimensional model of 13 items (see Table 1) with adequate psychometric properties for use on populations like the one under study. Each item is linked to five categories on an ordinal scale that goes from never (1) to always (5). The items include actions referring to helping (e.g., "I try to help others"); to sharing (e.g., "I easily lend money or other things"); to caring (e.g., "I try to be close and care for those who need it"); and to feeling empathy (e.g., "I easily put myself in the shoes of those who are in an awkward situation"). The internal consistency study applied to the instrument in Chile presented a Cronbach's alpha $=0.867$, lower than that obtained by the authors of the original scale in Italy (0.91); however, it also reflected suitable reliability.

Happiness was measured with the subjective happiness scale proposed by Lyubomirsky and Lepper (1999). The version translated and evaluated in Chile by Vera-Villarroel

TABLE 1 | Prosocialness scale for adults by Caprara et al. (2005) (adapted version).

\begin{tabular}{ll}
\hline 1. & I share my things with my friends. \\
2. & I try to help others. \\
3. & I am available for volunteer activities to help those in need. \\
4. & I help those in need right away. \\
5. & I do what I can to help others avoid getting into trouble. \\
6. & I feel what others feel intensely. \\
7. & I am willing to make my knowledge and skills available to others. \\
8. & I easily lend money and other things. \\
9. & I easily put myself in the shoes of those who are in an awkward \\
10. & I try to be close and care for those who need it. \\
11. & I spend time with those friends who feel lonely. \\
12. & I immediately feel it when my friends are uncomfortable, even \\
13. & when they do not communicate it to me directly.
\end{tabular}


et al. (2011) was used. It is a global measurement of subjective happiness. It focuses on the evaluation of a molar category of well-being in terms of an integral psychological phenomenon. It evaluates happiness from the respondent's point of view because it supposes that each subject has their own idea of happiness; moreover, they are able to discern if they are happy or not and report it (Lyubomirsky, 2008). It is an instrument comprised of four items (see Table 2), each linked to a seven-point Likert-type scale. The ends range from "not a very happy person" to "a very happy person" (item 1); "less happy" to "more happy" (item 2 ); and "not at all" to "a great deal" (items 3 and 4). The internal consistency study applied to the instrument in Chile showed a Cronbach's alpha $=0.78$ (Vera-Villarroel et al., 2011).

\section{Procedure}

Once the sample had been defined, contact was made with the directors and teachers in the programs the participants were enrolled in. The aims of the study were explained to them and their permission was sought to enter the classrooms and apply the instruments. Another option taken was to contact the students directly in other organizational units. Participation in the study was voluntary and anonymous and all the participants signed an informed consent. In this letter, the objectives and scopes of the investigation were explained. In addition, the confidentiality of the data was guaranteed. It should be noted that anonymity, along with protecting the identity of each participant, helps mitigate the effect of social desirability (Fisher, 1993). The surveys were applied in August and September 2019.

\section{Data Analysis}

A CFA was carried out using polychoric correlation matrix and the mean- and variance-adjusted unweighted least squares method. This method is recommended to analyze ordinal variables with a limited number of categories (Finney and Di Stefano, 2006; Forero et al., 2009).

The reliability indicators applied were Cronbach's alpha (1951) and the omega coefficient (McDonald, 1999). The latter was used to complement the former because Cronbach's alpha sees its reliability reduced when applied to ordinal variables (Elosua and Zumbo, 2008). It is also affected by sampling error (Ledesma, 2004). For this, Ventura-León and Caycho-Rodríguez (2017) propose complementing the

TABLE 2 | Subjective happiness scale by Lyubomirsky and Lepper (1999), translated and evaluated by Vera-Villarroel et al. (2011).

\footnotetext{
1. In general, I consider myself:

2. $\quad$ Compared with most of my peers, I consider myself:

3. Some people are generally very happy. They enjoy life regardless of what is going on, getting the most out of everything. To what extent does this characterization describe you?

4. Some people are generally not very happy. Although they are not depressed, they never seem as happy as they might be. To what extent does this characterization describe you?
}

measurement with the omega coefficient which, in contrast to the alpha coefficient, works with the factor loads and achieves more stable calculations (Gerbing and Anderson, 1988). In this context, omega coefficient values between 0.70 and 0.90 are considered acceptable (Campo-Arias and Oviedo, 2008).

To evaluate the goodness-of-fit of the model, the following indicators were used as: the comparative fit index (CFI), the Tucker-Lewis index (TLI), and the root mean-square error of approximation (RMSEA). From an interpretative perspective, the model presents a suitable fit when the CFI and the TLI display values over 0.90 (Schumacher and Lomax, 1996), whereas for the RMSEA values below 0.08 are considered adequate (Browne and Cudeck, 1993; Gouveia et al., 2018). The analyses were generated with the support of the Mplus program 7.11 (Muthén and Muthén, 2012).

\section{RESULTS}

The proposed model presented a good fit to the data, yielding the following values: $\mathrm{CFI}=0.951 ; \mathrm{TLI}=0.944$ and $\mathrm{RMSEA}=0.065$ (CI90\% $=0.0530 .078$ ).

The internal consistency indicators produced by the CFA for the prosocialness and subjective happiness scales were as: Cronbach's alpha $=0.843$ and 0.756 ; omega coefficient $=0.858$ and 0.839 , respectively.

Figure 1 summarizes the model, including the measurement variables with their factor loads and standard errors. The factor loads varied between 0.442 and 0.731 for prosocialness, and between 0.370 and 0.930 for subjective happiness, all statistically significant $(p<0.0001)$. The correlation between the prosocialness and subjective happiness scales was 0.338 and statistically significant $(p<0.0001)$.

The results yielded by the CFA applied confirmed a positive relation between prosocialness and happiness. In other words, the standards of prosocial behavior (Dovidio et al., 2006; Caprara and Steca, 2007; Eisenberg et al., 2015) reported by the participants, including its physical and emotional facets (Catalano et al., 2004; Caprara et al., 2005; Benson et al., 2006), were associated positively with their subjective happiness (Lyubomirsky and Lepper, 1999; Vera-Villarroel et al., 2011).

The instruments applied presented suitable levels of reliability. In the case of the adapted version of the prosocialness scale for adults by Caprara et al. (2005), the Cronbach's alpha, although lower than the one in the original study, was acceptable (Cronbach, 1951). In addition, the value produced by the omega coefficient (McDonald, 1999), applied according to the directions given by Ventura-León and Caycho-Rodríguez (2017), is also admissible (CampoArias and Oviedo, 2008). It also provides the results with greater stability (Gerbing and Anderson, 1988). This is due to the problems presented by the Cronbach's alpha when applied to ordinal variables (Ledesma, 2004; Elosua and Zumbo, 2008), like those in the present study.

In the same vein, the subjective happiness scale presented a slightly lower Cronbach's alpha than that of the validation 


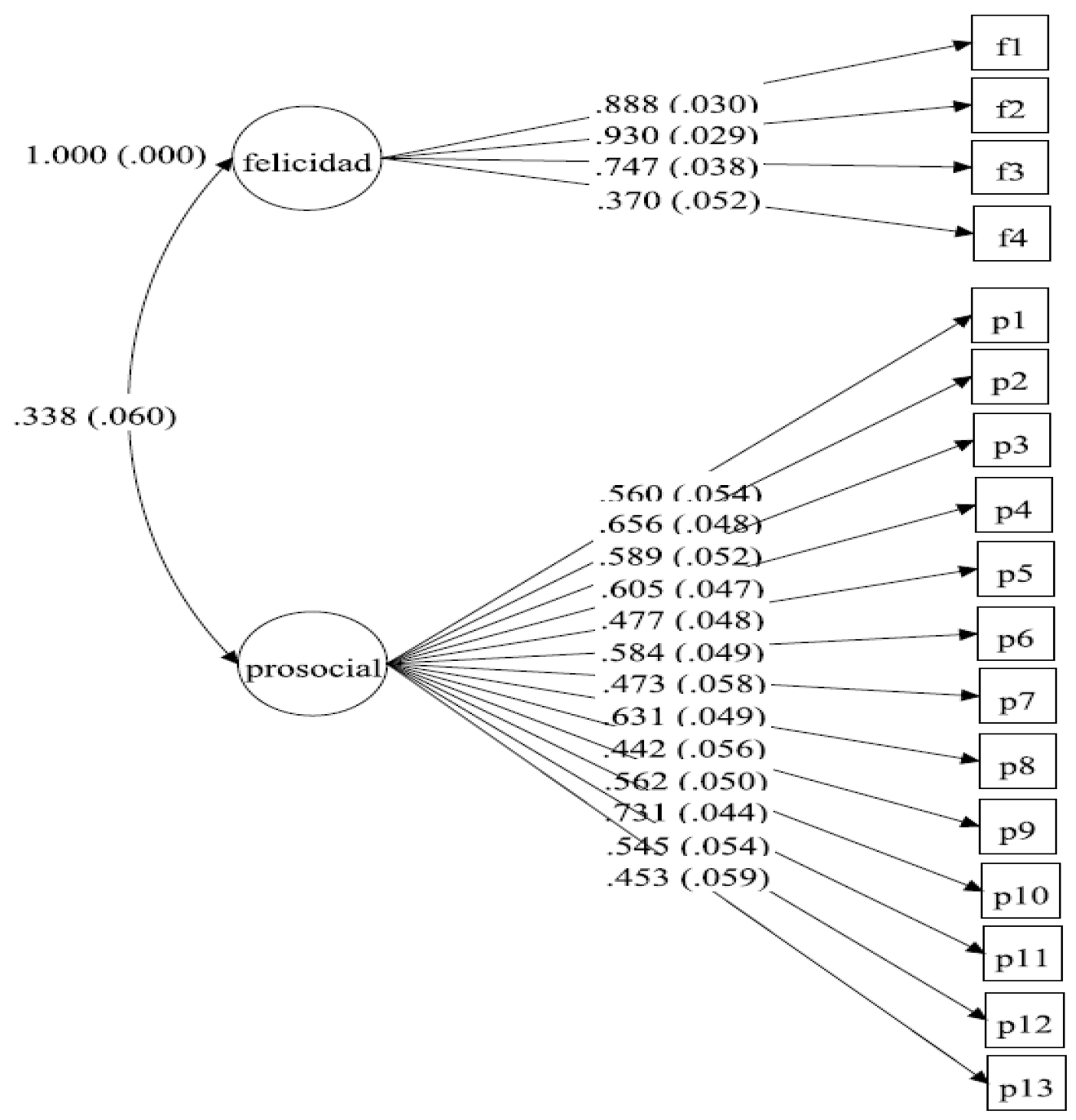

FIGURE 1 | Standardized results of the CFA applied to the model created by the authors with the support of Mplus 7.11 (Muthén and Muthén, 2012).

study conducted in Chile (0.756 vs. 0.780). The result of the omega coefficient - the advantages of which have already been explained - served to confirm what was indicated.

In relation to the goodness-of-fit indicators, both the CFI and the TLI were within the ranges that the literature considers acceptable (Schumacher and Lomax, 1996). The same occurred with the RMSEA value (Browne and Cudeck, 1993; Gouveia et al., 2018).

\section{DISCUSSION}

First of all, and on a general level, the positive relation between prosocialness and happiness was consistent with the results of other studies (Lyubomirsky, 2001; Lyubomirsky and Layous, 2013; Unanue et al., 2021). This extends to the economic dimension if it is considered that item 9 on the prosocialness scale for adults specifically refers to this
("I easily lend money or other things"). In this sense, this part of the results is in line with those studies that report a positive connection between prosocial economic behaviors associated with higher happiness levels (Aknin et al., 2020; Dunn et al., 2020). However, more research is needed to make a more definitive statement about this link. What could be truly interesting is if the focus was confined to a university education environment like that of students who have only limited resources. It could also anticipate the response by the subjects about being professionals, since the teaching profession is characterized by mid-level salaries. This is because the recently reviewed theoretical and empirical considerations could be applied to a specific professional area of great potential for the development of prosocial behaviors.

Second, if the discussion is limited to the education sphere, it is worth emphasizing the application of the instruments in a context of initial teacher training; particularly 
in the case of the prosocialness construct, where the preceding study has recommended the development and/or adaptation of measuring instruments to specific institutional areas (Auné et al., 2014), and in specific age groups, such as adulthood (Caprara et al., 2005), which is also interesting for the discussion, because the study participants can be classified as emerging adults (Barrera and Vinet, 2017). Moreover, their age distribution was consistent with the statistics produced by official entities (Ministerio de Educación de Chile, 2017). This is relevant because it is an evolutionary stage in search of identity and consolidation of characteristics that will accompany them into adult life. More importantly, however, is their future condition as teachers, added to implications that their prosocial standards may have for their later professional behavior; hence, confirming this relation anticipates prosocial behaviors in future professional work, which together with the link to happiness could result in better job satisfaction (Nielsen and Christensen, 2021). This is due to the increasing number of reports that place prosocialness as positively associated with socioemotional development (Baiocco et al., 2018; García and Tully, 2020), which in turn is related to a wide range of issues, such as the development of self-esteem (Garaigordobil and García De Galdeano, 2006), psychosocial adjustment (Eisenberg and Fabes, 1998; Xiong et al., 2021), and group integration (Plazas et al., 2010). Consequently, it is also related to better academic results (Bandura et al., 1996; Cappella et al., 2013; Flórez-Donado et al., 2018), which subsequently reinforces the indications that point out the relevance of socioemotional education in teacher training, which can amplify the effect of positive modeling they would have for their future students (Cefai et al., 2018; García-Vázquez et al., 2020; Zee et al., 2020; Oliveira et al., 2021; Sezen-Gultekin et al., 2021).

Third, the results lead to thinking about the social relevance of school and its potential to make substantive changes in individuals and therefore society. For example, in areas, such as civic education, if it is conceived not only as a cognitive exercise for learning concepts but also is stimulated with prosocial behaviors, its potential contribution in the formation of happier citizens is augmented (Simon and Mobekk, 2019; Lubian, 2020) and from multiple perspectives of happiness (Ryan and Deci, 2001; Keyes et al., 2002; Lyubomirsky, 2008; Waterman, 2008; Seligman, 2011; Goodman et al., 2018). At the same time, they would be more committed to the issues of their community and its development (Eisenberg et al., 2006; Grant and Dutton, 2012; Luengo et al., 2014). And in a reciprocal way, better conditions for the development of each individual would be established. This is in terms of the provision and internalization of resources to confront various life problems (Abbe et al., 2003; Lyubomirsky et al., 2005a,b) and thus to facilitate the construction of several personal and collective projects for happiness and a good life (Buss, 2000). Without a doubt, school is one of the socialization spaces to teach these behaviors and put them into practice, especially if it is considered that the development of social skills, the ability for self-regulation, and self-esteem is important for personal growth. This becomes a valuable resource to tackle complex events like intimidation and harassment (GarcíaVázquez et al., 2020). In all these processes, the facilitating and modeling role of teachers can be fundamental in terms of their leadership and proximity to the possible beneficiaries of their actions (Chancellor et al., 2018; Deng et al., 2021), especially with respect to their contributions to establishing a suitable school climate and its resulting beneficial effects (Cohen et al., 2009; Thapa et al., 2013; Luengo et al., 2017).

Thus, the behaviors focused on the benefit of others are fundamental to promoting education, safeguarding health, and combatting poverty and hunger (Grant and Dutton, 2012). Several studies recommend introducing social policies that promote the development of prosocial competences and behaviors to increase children's happiness (Baiocco et al., 2018). At the same time, the recognition of these expressions should be fostered from an early age, since they provide positive opportunities for socialization (García and Tully, 2020). This addresses the processes of initial teacher training directly because students' socioemotional development requires the social and emotional training of the teachers (Cefai et al., 2018; García-Vázquez et al., 2020; Zee et al., 2020; Oliveira et al., 2021; SezenGultekin et al., 2021).

\section{CONCLUSION}

This study evaluated the relation between prosocialness and subjective happiness in a sample of student teachers at a university in the Region of La Araucanía, Chile. The proposed model presented suitable levels of reliability and fit.

Although the sample size was acceptable in terms of the number of items considered, the non-probabilistic nature of the study does not permit these results to be generalized to the rest of the population. This trait is the most relevant limitation of this study. It should be added that the searched data were self-reported by the participants with the resulting impact that social desirability and memory bias could have had on the responses. Finally, the homogenizing nature of the scale responses does not account for the inherent specificities that social phenomena have, always located territorially and historically.

However, the evaluated model forms a basic line for the development of future investigations referring to the relation between prosocialness and happiness in the field of teacher training. Given the dynamics that these constructs represent in relation to the evolution of life, longitudinal studies are recommended that incorporate more variables. For example, age (in more specific ranges), gender, ethnic group, and the effects of the curriculum and the teaching specialty, among others. On the last point, the coordination of training proposals referring to the development of socioemotional skills with their corresponding evaluations would be interesting given the increasing number of investigative reports that recommend their inclusion in the teacher training curriculum. 


\section{DATA AVAILABILITY STATEMENT}

The original contributions presented in the study are included in the article/supplementary files, further inquiries can be directed to the corresponding author.

\section{ETHICS STATEMENT}

Ethical approval was not provided for this study on human participants because it is a preliminary study to the development of a doctoral thesis. The doctoral thesis project was submitted to the Scientific Ethics Committee of the University of La Frontera. The patients/participants provided their written informed consent to participate in this study.

\section{REFERENCES}

Abbe, A., Tkach, C., and Lyubomirsky, S. (2003). The art of living by dispositionally happy people. J. Happiness Stud. 4, 385-404. doi: 10.1023/B:JOHS.0000005769. $54611.3 \mathrm{c}$

Aknin, L., Dunn, E., Proulx, J., Lok, I., and Norton, M. (2020). Does spending money on others promote happiness?: a registered replication report. J. Pers. Soc. Psychol. 119, e15-e26. doi: 10.1037/pspa0000191

Auné, S. E., Blum, D., Abal-Facundo, J. P., Lozzia, G. S., and Attorresi, H. F. (2014). La conducta prosocial: estado actual de la investigación. Revista Perspectivas En Psicología 11, 21-33.

Baiocco, R., Verrastro, V., Fontanesi, L., Ferrara, M., and Pistella, J. (2018). The contributions of self-esteem, loneliness, and friendship to children's happiness: the roles of gender and age. Child Indic. Res. 12, 1413-1433. doi: $10.1007 /$ s12187-018-9595-7

Bandura, A., Barbaranelli, C., Caprara, G., and Pastorelli, C. (1996). Multifaceted impact of self-efficacy beliefs on academic functioning. Child Dev. 67, 1206-1222. doi: 10.2307/1131888

Barrera, A., and Vinet, E. (2017). Adultez Emergente y características culturales de la etapa en universitarios chilenos. Terapia Psicológica 35, 47-56. doi: 10.4067/S0718-48082017000100005

Benson, P. L., Scales, P. C., Hamilton, S. F., and Sesma, A. (2006). "Positive youth development: theory, research and applications," in Theoretical Models of Human Development. Handbook of Child Psychology. ed. R. M. Lerner (United States: Wiley), 894-941.

Browne, M., and Cudeck, R. (1993). "Alternative ways of assessing model fit," in Testing Structural Equation Models. eds. K. Bollen and J. Long (California: Sage), 136-162.

Buss, D. M. (2000). The evolution of happiness. Am. Psychol. 55, 15-23. doi: 10.1037/0003-066X.55.1.15

Campo-Arias, A., and Oviedo, H. (2008). Propiedades psicométricas de una escala: la consistencia interna. Revista Salud Pública 10, 831-839. doi: 10.1590/ S0124-00642008000500015

Cappella, E., Kim, H., Neal, J., and Jackson, D. (2013). Classroom peer relationships and behavioral engagement in elementary school: the role of social network equity. Am. J. Community Psychol. 52, 367-379. doi: 10.1007/s10464-013-9603-5

Caprara, G. V., and Steca, P. (2007). Prosocial agency: the contribution of values and self-effi cacy beliefs to prosocial behavior across ages. J. Soc. Clin. Psychol. 26, 218-239. doi: 10.1521/jscp.2007.26.2.218

Caprara, G. V., Steca, P., Zelli, A., and Capanna, C. (2005). A new scale for measuring adults' prosocialness. Eur. J. Psychol. Assess. 21, 77-89. doi: 10.1027/1015-5759.21.2.77

Catalano, R., Berglund, M., Ryan, J., Lonczak, H., and Hawkins, D. (2004). Positive youth development in the United States: research findings on evaluations of positive youth development programs. Ann. Am. Acad. Politic. Soc. Sci. 591, 98-124. doi: 10.1177/0002716203260102

Cefai, C., Bartolo, P., Cavioni, V., and Downes, P. (2018). "Strengthening social and emotional education as a core curricular area across the EU: a review

\section{AUTHOR CONTRIBUTIONS}

MM-C created the research question, conducted a bibliographic search, theoretical framework, methodological design, data analysis, and contributed to the discussion. SS-G contributed the methodological design, data analysis, and discussion. MD contributed to the theoretical framework, methodological design, and discussion. All authors contributed to the article and approved the submitted version.

\section{FUNDING}

This work was produced within the framework of FONDECYT project no. 1210551 .

of the international evidence," in NESET II Report (Luxembourg: Publications Office of the European Union)

Chancellor, J., Margolis, S., and Lyubomirsky, S. (2018). The propagation of everyday prosociality in the workplace. J. Posit. Psychol. 13, 271-283. doi: 10.1080/17439760.2016.1257055

Cohen, J., McCabe, E. M., Michelli, N. M., and Pickeral, T. (2009). School climate: research, policy, teacher education and practice. Teach. Coll. Rec. $111,180-213$.

Cronbach, L. (1951). Coefficient alpha and the internal structure of tests. Psychometrika 16, 297-334. doi: 10.1007/BF02310555

Deng, N., Bi, H., and Zhao, J. (2021). Maternal psychological control and rural left-behind children's anxiety: the moderating role of externalizing problem behavior and teacher support. Front. Psychol. 12:624372. doi: 10.3389/ fpsyg.2021.624372

Dovidio, J. F., Piliavin, J. A., Schroeder, D. A., and Penner, L. A. (2006). The Social Psychology of Prosocial Behavior. New York: Laurence Erlbaum Associates.

Dunn, E., Whillans, A., Norton, N., and Aknin, L. (2020). "Prosocial spending and buying time: money as a tool for increasing subjective well-being," in Advances in Experimental Social Psychology. Vol. 61. ed. B. Gawronski (New York: Academic Press Inc.), 67-126.

Eisenberg, N., and Fabes, R. (1998). "Prosocial development," in Social, Emotional, and Personality Development. Volume 3 of the Handbook of Child Psychology. ed. N. Eisenberg (United States: Wiley), 701-778.

Eisenberg, N., Fabes, R. A., and Spinrad, T. L. (2006). "Prosocial development," in Handbook of Child Psychology: Social, Emotional, and Personality Development. Vol. 3. eds. W. Damon and R. M. Lerner (United States: Wiley), 646-718.

Eisenberg, N., Spinrad, T., and Knafo-Noam, A. (2015). "Prosocial Development," in Handbook of Child Psychology and Developmental Science. Volume 3. Socioemotional Processes. eds. M. Lamb and R. Lerner (United States: Wiley), 610-656.

Elosua, P., and Zumbo, B. (2008). Coeficientes de fiabilidad para escalas de respuesta categórica ordenada. Psicothema 20, 896-901.

Finney, S., and Di Stefano, C. (2006). "Nonnormal and categorical data in structural equation modeling," in Structural Equation Modeling. A Second Course. eds. G. Hancock and R. Mueller (Charlotte, NC: Information Age Publishing), 269-314.

Fisher, R. (1993). Social desirability bias and the validity of indirect questioning. J. Consum. Res. 20, 303-315. doi: 10.1086/209351

Flórez-Donado, J., López, L. S., Peña, D., Torres-Salazar, P., Mejía, E. A., Narváez, A. M., et al. (2018). Competencia social como predictor de éxito escolar. Revista Espacios 39:14.

Forero, C. G., Maydeu-Olivares, A., and Gallardo-Pujol, D. (2009). Factor analysis with ordinal indicators: a Monte Carlo study comparing DWLS and ULS estimation. Struct. Equ. Model. 16, 625-641. doi: 10.1080/10705510903203573

Garaigordobil, M., and García De Galdeano, P. (2006). Empatía en niños de 10 a 12 años. Psichotema 18, 180-186. 
García, S., and Tully, E. (2020). Children's recognition of happy, sad, and angry facial expressions across emotive intensities. J. Exp. Child Psychol. 197, 1-17. doi: $10.1016 /$ j.jecp.2020.104881

García-Vázquez, F. I., Valdés-Cuervo, A. A., Martínez-Ferrer, B., and Parra-Pérez, L. G. (2020). Forgiveness, gratitude, happiness, and prosocial bystander behavior in bullying. Front. Psychol. 10:2827. doi: 10.3389/ fpsyg.2019.02827

Gerbing, D., and Anderson, J. (1988). An update paradigm for scale development incorporating unidimentionality and its assessment. J. Mark. Res. 25, 186-192. doi: $10.1177 / 002224378802500207$

Goodman, F. R., Disabato, D. J., Kashdan, T. B., and Kauffman, S. B. (2018). Measuring well-being: a comparison of subjective well-being and PERMA. J. Posit. Psychol. 13, 321-332. doi: 10.1080/17439760.2017.1388434

Gouveia, V. V., de Moura, H. M., de Oliveira Santos, L. C., do Nascimento, A. M., de Oliveira Guedes, I., and Gouveia, R. S. (2018). Escala de Autorrelato de Trapaça-Admissão: evidências de validade fatorial e precisão. Revista Colombiana de Psicología 27, 27-40. doi: 10.15446/rcp.v27n1.64467

Grant, A., and Dutton, J. (2012). Beneficiary or benefactor: are people more prosocial when they reflect on receiving or giving? Psychol. Sci. 23, 1033-1039. doi: $10.1177 / 0956797612439424$

Keyes, C. L. M., Shmotkin, D., and Ryff, C. D. (2002). Optimizing well-being: the empirical encounter of two traditions. J. Posit. Psychol. 82, 1007-1022. doi: 10.1037/0022-3514.82.6.1007

Krettenauer, T., Bauer, K., and Sengsavang, S. (2019). Fairness, prosociality, hypocrisy, and happiness: children's and adolescents' motives for showing unselfish behaviour and positive emotions. Br. J. Dev. Psychol. 37, 505-518. doi: $10.1111 /$ bjdp.12289

Lai, W., Yang, Z., Mao, Y., Zhang, Q., Chen, H., and Ma, J. (2020). When do good deeds Lead to good feelings? Eudaimonic orientation moderates the happiness benefits of prosocial behavior. Int. J. Environ. Res. Public Health 17, 1-12. doi: 10.3390/ijerph17114053

Ledesma, R. (2004). AlphaCI: un programa de cálculo de intervalos de confianza para el coeficiente alfa de Cronbach. Psico-USF 9, 31-37. doi: 10.1590/ S1413-82712004000100005

Lévy, J. P., and Varela, J. (2006). Modelización con Estructuras de Covarianza en Ciencias Sociales. Temas Esenciales, Avanzados y Aportaciones Especiales. Spain: Netbiblo, S. L..

Lubian, D. (2020). Are virtuous people happier? Evidence from Italy. Econ. Soc. 13, 146-164. doi: 10.14254/2071-789X.2020/13-1/10

Luengo, B., Eisenberg, N., Thartori, E., Pastorelli, C., Uribe, L., Gerbino, M., et al. (2017). Longitudinal relations Among positivity, perceived positive school climate, and prosocial behavior in Colombian adolescents. Child Dev. 88, 1100-1114. doi: 10.1111/cdev.12863

Luengo, B., Pastorelli, C., Zuffiano, A., Eisenberg, N., Ceravolo, R., and Caprara, G. (2014). Trajectories of prosocial behaviors conducive to civic outcomes during the transition to adulthood: the predictive role of family dynamics. J. Adolesc. 37, 1529-1539. doi: 10.1016/j.adolescence.2014.07.002

Lyubomirsky, S. (2008). La ciencia de la Felicidad. Un método probado para conseguir el bienestar. Barcelona: Urano.

Lyubomirsky, S. (2001). Why are some people happier than others? The role of cognitive and motivational processes in well-being. Am. Psychol. 56, 239-249. doi: 10.1037/0003-066X.56.3.239

Lyubomirsky, S., King, L., and Diener, E. (2005a). The benefi ts of frequent positive affect: does happiness lead to success? Psychol. Bull. 131, 803-855. doi: 10.1037/0033-2909.131.6.803

Lyubomirsky, S., and Layous, K. (2013). How do simple positive activities increase well-being? Curr. Dir. Psychol. Sci. 22, 57-62. doi: 10.1177/ 0963721412469809

Lyubomirsky, S., and Lepper, H. S. (1999). A measure of subjective happiness: preliminary reliability and construct validation. Soc. Indic. Res. 46, 137-155. doi: 10.1023/A:1006824100041

Lyubomirsky, S., Sheldon, K. M., and Schkade, D. (2005b). Pursuing happiness: the architecture of sustainable change. Rev. Gen. Psychol. 9, 111-131. doi: 10.1037/1089-2680.9.2.111

McDonald, R. (1999). Test Theory: A Unified Treatment. New Jersey: Lawrence Erlbaum Associates.

Ministerio de Educación de Chile. (2017). Estadísticas de la educación 2016. Santiago: MINEDUC.
Muthén, L., and Muthén, B. (2012). Mplus Statistical Analysis With Latent Variables. User's Guide. 7th Edn. Los Angeles, CA: Muthén and Muthén.

Nielsen, K., and Christensen, M. (2021). Positive participatory organizational interventions: a multilevel approach for creating healthy workplaces. Front. Psychol. 12:696245. doi: 10.3389/fpsyg.2021.696245

Oliveira, S., Roberto, M. S., Pereira, N. S., Marques-Pinto, A., and Veiga-Simão, A. M. (2021). Impacts of social and emotional learning interventions for teachers on teachers' outcomes: a systematic review with meta-analysis. Front. Psychol. 12:677217. doi: 10.3389/fpsyg.2021.677217

Plazas, E. A., Morón Cotes, M. L., Santiago, A., Sarmiento, H., Ariza López, S. E., and Patiño, C. D. (2010). Relaciones entre iguales, conducta prosocial y género desde la educación primaria hasta la universitaria en Colombia. Universitas Psychologica 9, 357-369. doi: 10.11144/Javeriana.upsy9-2.ricp

Ryan, R. M., and Deci, E. L. (2001). On happiness and human potentials: a review of research on hedonic and eudaimonic well-being. Annu. Rev. Psychol. 52, 141-166. doi: 10.1146/annurev.psych.52.1.141

Schumacher, R., and Lomax, R. (1996). A Beginner's Guide to Structural Equation Modeling. New Jersey: Lawrence Erlbaum Associates.

Seligman, M. (2011). Flourish: A Visionary New Understanding of Happiness and Well-Being. London: Free Press.

Sezen-Gultekin, G., Bayrakc1, M., and Limon, I. (2021). The mediating role of organizational commitment on the relationship Between emotional labor and work engagement of teachers. Front. Psychol. 12:648404. doi: 10.3389/ fpsyg.2021.648404

Simon, C., and Mobekk, H. (2019). Norwegian, Dugnad: A fact and a narrative of behavior, prosocial. Pers. Behav. Sci. 42, 815-834. doi: 10.1007/s40614-019-00227-w

Thapa, A., Cohen, J., Guffey, S., and Higgins-D’Alessandro, A. (2013). A review of school climate research. Rev. Educ. Res. 83, 357-385. doi: 10.3102/0034654313483907

Toro, I., and Parra, R. (2010). Fundamentos epistemológicos de la investigación y la metodología de la investigación Cualitativa-Cuantitativa. Medellín: Fondo Editorial Universidad EAFIT.

Unanue, W., Barros, E., and Gómez, M. (2021). The longitudinal link between organizational citizenship Behaviors and three different models of happiness. Int. J. Environ. Res. Public Health 18:6387. doi: 10.3390/ijerph18126387

Ventura-León, J., and Caycho-Rodríguez, T. (2017). El coeficiente Omega: un método alternativo para la estimación de la confiabilidad. Revista Latinoamericana de Ciencias Sociales, Niñez y Juventud 15, 625-627.

Vera-Villarroel, P., Celis-Atenas, K., and Córdova-Rubio, N. (2011). Evaluación de la Felicidad: Análisis Psicométrico de la Escala de Felicidad Subjetiva en Población Chilena. Terapia Psicológica 29, 127-133. doi: 10.4067/ S0718-48082011000100013

Waterman, A. S. (2008). Reconsidering happiness: a eudaimonist's perspective. J. Posit. Psychol. 3, 234-252. doi: 10.1080/17439760802303002

Xiong, M., Xiao, L., and Ye, Y. (2021). Relative deprivation and prosocial tendencies in Chinese migrant children: testing an integrated model of perceived social support and group identity. Front. Psychol. 12:658007. doi: 10.3389/fpsyg.2021.658007

Zee, M., Rudasill, K. M., and Roorda, D. L. (2020). "Draw me a picture". Studentteacher relationship drawings by children displaying externalizing, internalizing, or prosocial behavior. Elem. Sch. J. 120, 636-666. doi: 10.1086/708661

Conflict of Interest: The authors declare that the research was conducted in the absence of any commercial or financial relationships that could be construed as a potential conflict of interest.

Publisher's Note: All claims expressed in this article are solely those of the authors and do not necessarily represent those of their affiliated organizations, or those of the publisher, the editors and the reviewers. Any product that may be evaluated in this article, or claim that may be made by its manufacturer, is not guaranteed or endorsed by the publisher.

Copyright (c) 2021 Mieres-Chacaltana, Salvo-Garrido and Denegri. This is an openaccess article distributed under the terms of the Creative Commons Attribution License (CC BY). The use, distribution or reproduction in other forums is permitted, provided the original author(s) and the copyright owner(s) are credited and that the original publication in this journal is cited, in accordance with accepted academic practice. No use, distribution or reproduction is permitted which does not comply with these terms. 